\title{
Influencing Positive Outcomes For Troubled Youth
}

\author{
Diane Haggis, BHB Education Consulting, USA
}

\begin{abstract}
The BHB Theory (Haggis, 2011) is based on an empirical case study that examined teachers' perceptions of what they do in their educational settings to create a positive learning environment for troubled youth in their classrooms. Research - including this study-indicates a need for transformational change in how teachers interrelate with students in education environments intended for at risk-youth.

Traditionally, approaches to working with troubled youth have been punitive in design. Research indicates that this approach is counterproductive and that teachers have the opportunity to build capacity for success with at risk-youth through the use of peers; building social competencies; role modeling; relationship building; setting high expectations and fostering student strengths. Understanding what effective teachers working with troubled youth do to create a positive learning environment in their classrooms is critical for identifying factors that influence a positive outcome for students in such programs.

The descriptive case study described utilized a mixed methods approach using teachers within two residential schools.

The BHB study's data analysis discovered that there was significant agreement among the teacher participants of the study about factors perceived as strongly influential in creating a positive learning environment for their students. Consistent with prior research, these factors included providing a classroom atmosphere that supports positive peer relationships, setting high expectations for student success, encouraging students to take responsibility for their own actions, strong relationship building and generating an environment of trust and respect.
\end{abstract}

Recommendations for strengthening teacher practice are offered.

Keywords: At Risk Youth/Troubled Youth; Relationship Building; Positive Learning Environment; Teacher Perceptions

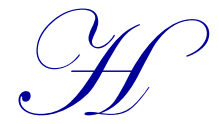

ow can teachers influence negative behavior in school for at risk-youth? What are effective strategies for working with children with a history of failure - in most aspects of their life - which influence their trust and confidence in succeeding in school? What do effective teachers do to stimulate a positive learning environment in their classrooms for such students?

\section{Context of the Study}

Students who are residential, or in alternative education placements, often have a history of not only school failure but challenges in every aspect of their lives. These type of youth present a challenge regarding how to motivate them to be invested in their learning because they have often had very negative experiences in school. These are the kids often suspended, often absent from school, often very unsuccessful. Even when they do go to school, their relationship with the school system is often tainted with negative feelings, a lack of trust and feelings of inadequacy. Teachers who work successfully with these students deserve a great deal of respect because although all kids need a good teacher, these students need not only a good teacher but a belief that a good teacher can help them succeed in school. Research indicates that this can be accomplished through hard work, use of social skills and the building of relationships. Even the toughest kids respond to those efforts. In my personal experience as a teacher and then an administrator in three separate institutional settings for troubled youth, I have witnessed some masterful teachers be able to reach kids - and conversely - I have seen some pretty negative interactions between adults and kids in school. 
The importance of both positive and negative interactions between adults and students can highly influence student behavior.

What makes one teacher or adult more successful than another with this type of population? Is it the kids? Is it the structure? Is it the culture of the classroom?

The research study which led to the BHB Theory (Bonding, High Expectations and Belief in Success) (Haggis, 2011) addresses this issue. The BHB theory, as well as a significant amount of other research, asserts that teachers set the tone for the classroom and establish the academic and behavioral guidelines.

Bonding, High Expectations and Belief in Success

The BHB Theory asserts that when working with youth with a history of academic, social and emotional challenges, the teacher has the power to change the climate of the classroom and promote intrinsic motivation. To help troubled youth become responsible, productive people who can meet with success in society, youth need certain skills that teachers can help develop. Among them are social skills, empathy for others and taking responsibility for their actions. Additionally, other researchers stress that teachers can highly influence the classroom environment. Researchers, including Vorrath and Brendtro (2005); Laursen (2005); Burns and Hoagwood (2002), all report that mobilizing the inner power of youth can build a desire to connect with others and help create caring relationships - which ultimately can positively influence success in school.

Although literature supports the concept of how important teachers and schools are in motivating at risk-youth, there is not a great deal of literature that identifies what specific teacher practice promotes this environment and what it looks like in the classroom.

Therefore, the BHB theory (and the study that led to the development of the theory) is significant in its attempt to further research by providing a glimpse into effective teacher practice when working with troubled youth.

The study examines:

Teacher perception of what they do in their institutionalized settings to create a positive learning environment for troubled youth in their classrooms. More specifically, teacher descriptions of what they do in their classrooms to foster a positive learning environment was reported through the lens of 3 theories: Positive, Peer Culture (Vorrath \& Brendtro, 2005) which refers to the control youth have over one another's attitudes, values and behavior; Positive Behavior Supports (Christle, Joliette and Nelson, 2005) which refers to behavior such as helping one another, appropriate problem solving and sharing, social skills development and the Resiliency Theory (Krovetz, 1999) which refers to the ability of troubled youth to overcome adversity by using their inner strengths (Haggis, 2011).

In researching these theories, all three have some similar components and all three have value in changing the culture of a school environment for troubled youth.

Positive Peer Culture (Vorrath \& Brendtro, 2005) focuses on the power of peers to learn to offer each other acceptance and encouragement. The theory speaks to demanding greatness instead of obedience - meaning that teacher should have high expectations for youth. Another component of PPC is assigning responsibility for change which refers to adults inspiring youth to take responsibility for their actions. The concept of PPC stresses that teachers can help students develop a sense of belonging by emphasizing their positive characteristics and rather than demand absolute obedience, nurture the student and set high expectations with positive interactions with students.

The second component of the triadic synthesized conceptual framework is Positive Behavior Support theory, specifically based on Christle, Joliette and Nelson (2002). The idea is that proactive systems of PBS assist youth in developing appropriate social skills which will aid their success. Because PBS is a system tailored to the individual needs of a child, it can help create individual behavior plans to promote conflict resolution and social interaction. 
The third and final component of the triadic conceptual framework is the Resiliency Theory. To develop resilience, research shows that adolescents need to be cared for and supported by adults in a school. Krovetz (1999) reports that resilient students have positive attitudes because they believe that if they try, it is possible to succeed. Research is clear on this point. Sagor (1996) states that competence, belonging, usefulness and optimism describe the difference between children who are positive and social versus those who are withdrawn negative and antisocial.

Teachers can develop strategies to build resiliency by structuring opportunities that enable youth to experience feelings of competence, belonging, usefulness and optimism. Harvey (2007) states that teachers need to form positive relationships with kids. They must deliberately, genuinely communicate positive regard.

The BHB Theory asserts that all of these components in all three theories are necessary to create a learning environment that promotes establishing positive practice with at risk youth. Therefore, the theory contends that a blend of peers offering each other acceptance, encouragement, teachers providing opportunities for meaningful participation in the classroom, positive adult role modeling and relationship building, social skills training and acceptance fosters enhanced self-esteem and respect. Hence the theory of BHB - Bonding, High Expectations and Belief in Success.

The research case study was designed to test this premise. The BHB Theory (Haggis, 2011) is the conceptual synthesis that guided the study and may provide a beneficial guide for teacher behavior that will positively influence the troubled youth in their classrooms. Educators and educational research focus a lot of attention on student behavior. But is equally critical to identify adult behavior that is effective when dealing with at risk youth.

Much has been written about enhancing behavior, motivation and success for students in regular education settings, however, studies for students in institutional or alternative settings are less well documented. The literature available clearly indicates a need for a change in the way teachers interact with all students. Persuasive empirical research indicates that a positive school environment promotes student academic achievement and healthy learning environments.

Research shows that zero tolerance and punitive measures when dealing with troubled youth is counterproductive. A 2000 report from the Advancement Project at Harvard University reported that their study found that suspended students are more likely to do poorly in school, eventually drop out, commit crimes in the future and be incarcerated as adults. Conversely, teachers who work well with troubled youth can help them develop skills necessary to change negative behavior without threats or punitive measures. Many professionals have talked about this including Dr. Marvin Marshall, whose book "Discipline Without Stress, Punishments or Rewards", 2005, states that it is critical to be positive to communicate in such a way as to improve relationships. Creating a positive learning environment reduces stress which is necessary in order to influence others.

A look at the historical view of the relationship between school and troubled youth provides a link between research known for at least 20 years, its connection to current literature and the acknowledgment that effective teacher practices can positively affect life choices of at risk-youth. A report written by the American Psychological Zero Tolerance Task Force in 2008 identifies disagreements that have arisen in the punitive manner schools handle disruptive youth. Additional research suggests that life is built on social interactions and that instead of dealing punitively with youth, adults must help youth build capacity to be integrated into society through encouragement, good role modeling and practice. Such skills can help youth build confidence and overcome past struggles.

It is critically important to understand the impact teachers can have on troubled youth.

The BHB study - which was validated with research - shows that teachers working with at-risk youth have the opportunity to build student capacity for success by using peers; building social competencies; relationship building; high expectations and fostering student strengths.

What dos that look like in a classroom? Think about the basic needs of every human being. According to Dr. William Glasser, who wrote a book entitled "The Choice Theory" (1998), the five basic human needs are: need to survive; need to belong; need to gain power; need to be free and need for fun. Glasser stated that people's perceptions guide 
their behavior. If that is true, how does it play out in the classroom and can adults use that knowledge to assist students in meeting these needs? If a student has a history of trauma, his/her survival instincts are at peak. Can a teacher help that student feel safe by treating him with respect? If a youth has a need to belong, can a teacher foster that need to belong by creating opportunities in the classroom for kids to work together which would not only assist with belonging but with strengthening peer to peer relationships and social skills? What if a youth needs power? Is he/she acting out to show that they have power? Can a teacher offer the youth choices in a classroom environment that empower them without their need to show power? Would having choices in a classroom make a youth feel important? And if he/she feels important, would this help him/her build trust?

Building relationships, being positive, encouraging rather than disciplining is the way to reach these youth. Within the culture of residential facilities, or school environments for at risk-youth, teachers must implement educational programming to youth who have been placed for non-educational reasons or often have a history of school failure. Understanding what teachers in these settings do to create a positive learning environment is critical to identifying factors that influence positive outcomes for students in such programs.

The BHB research study (Haggis, 2011) attempted to present a picture of effective classroom practices when working with troubled youth. The role of the teacher cannot be overstated.

There is overwhelming research that suggests that quality education is one of the most effective forms of crime prevention there is. Research by Scott et al. (2002) reports that teachers facilitate success by teaching meaningful skills at the level of the student, using appropriate instructional strategies and developing a positive classroom climate. They reported that it is here that students learn not only academic skills but enhance personal qualities, motivation and problem-solving skills.

The instrumentation for the BHB study included a teacher survey which was used to obtain baseline data for teachers of troubled youth and look for correlation of their responses to survey items with the conceptual framework for this study. All teachers in two residential settings were invited to participate. $77 \%$ chose to participate. The next component was an interview of select teachers chosen through three criteria: 1) principal recommendation of teachers with exemplary practice; 2) some type of colleague acknowledgement such as teachers who had been nominated for teacher of the year etc. and 3) alignment of survey answers with the conceptual framework. Those interviewed were also asked to write a Philosophy of Teaching Statement where I looked for correlation with the conceptual framework. Each instrument was pilot tested to ensure validity and reliability. Coding of themes was used to check validity and the combination of semi-structured questions with open-ended questions was used to look for patterns.

Results of the BHB research showed strong evidence from both schools (97.6\%) that there was value to using the influence of peers in creating a positive learning environment. Teachers gave examples of using peers to help one another in the classroom, assist one another in a crisis and build stronger social skills through positive interaction with peers. Empowering the students to work together created a more caring environment within the classroom (coprojects, joint assignments, mixed ability groupings, etc.). Teachers provided an opportunity for group work, and they emphasized doing this in a safe and non-threatening classroom environment. Having high expectations for students was an important factor for teacher participants in this study. Findings in the survey section, for example, showed that these teachers had high standards regarding academic success and behavior expectations. They were consistent with their expectations and routines and responses. Regarding academics, teachers emphasized the need for creating lessons that held students accountable for content commensurate with their ability.

Teachers said that youth must take responsibility for their actions so that they can learn from their mistakes and build social skills through positive interactions with others. Teachers looked for ways for misbehaved youth to repair the relationship (in a non-punitive manner) so that the consequence equals learning. A student who had a misbehavior with another peer, for example, might participate in peer mediation, conflict resolution classes or write a letter of apology. Teachers emphasized helping students learn from their experiences rather than simply punishing them.

There was consistency also in the Philosophy of Teaching Statement in their alignment with the belief that teachers have a responsibility to create an environment where students feel safe to express themselves. The teacher's role is to inspire learning. Several examples identified for empowering students included having children participate in creating 
classroom rules; each setting their own goals; and allowing students' choice in the classroom. All actions to strengthen the students' independence and empower them to have some ownership in their individual learning. Additionally, teachers stressed the need for adult role modeling. Teachers in the study saw themselves as playing a critical role in creating an environment where students learn once there was trust built between teacher and students. How adults interact with kids was seen as a strong contributor to the school climate. Treating students with respect, having high expectations, teaching children to work together was seen as critical for having youth become invested in learning. Teachers in both schools reported the need for adults to demonstrate a belief in student success by being a positive role model and promoting responsibility. Teachers can guide children by establishing opportunities for problem solving and decision making and that empowers them to believe in themselves. Students who believe that their teachers truly think they can be successful are more apt to try harder in the classroom.

Additionally, by designing well prepared differentiated, effective lessons where students can highlight their strengths, teachers stated that youth begin to see themselves as successful. Teachers in both settings included in the study offered insights as to the importance of lessons applicable to real life helped peek student interest and helped youth stay focused. To build capacity to overcome adversity, teachers in the study said that students need to realize common goals and see themselves as part of a team.

Recommendations for practice from the BHB study included the suggestion that teachers who want to improve peer to peer relationships in the hope of promoting an environment within the classroom for at-risk youth where students can positively influence each other, must start by setting a tone of open communication within the classroom. Creating such a climate can only be accomplished within an environment of trust. To develop a climate of trust, teachers must be consistent and fair when dealing with youth in their charge.

The results of the BHB study clearly highlighted evidence that to promote positive student behavior in residential or alternative programs, schools need more than a punitive approach with troubled youth. They need to develop behavior management systems that emphasize interventions producing long-term solutions focusing on student strengths, positive student-teacher interactions, and strong social skills. These results mirror those of Vincent, Houlihan and Zwart (1996) who reported that "children with skills deficits either lack the necessary social skills to interact appropriately with peers, or they omit a critical step in the performance of that skill" (p.101). They suggested, and the BHB study confers, that role modeling, coaching and allowing opportunities for positive peer interaction are appropriate interventions needed to build stronger self-control skills that will help reduce anxiety that interferes with the success of the youth.

Consistent with prior research, the BHB study concluded that teachers in institutions or alternative settings must maintain high standards for both academic and behavioral expectations and to accomplish this goal, teachers must set the tone and nature of the classroom as a positive learning environment. Results from the study are consistent with research by Van Petegem, Keer and Yves (2008) who stated that "interpersonal relationships between teachers and students are an important aspect of the classroom climate" (p.279). Teachers can set a tone for success for students through positive role modeling and consistency.

One strong common denominator highlighted throughout the study involved resiliency centered habits. Teachers in the study identified the need to believe that the students could achieve and be successful. Participants in the study indicated that this was a core component of establishing a positive learning environment.

The common theme of the research study was developing respect. Respect for education, respect for children's needs and respect for allowing all students to grow and develop in a safe and secure learning environment. It was quite evident throughout the research study that the teachers saw themselves as a pivotal force in creating an opportunity for student growth no matter the past experiences of the students. Bonding, High Expectations, and Belief in Success are all critical components of an effective classroom where students can learn, build trust and strengthen their ability to be successful in school. 


\section{AUTHOR BIOGRAPHY}

Dr. Diane Haggis, author of the BHB Theory (Bonding, High Expectations and Belief in Success) has over thirty six years of experience in education, twenty of which was spent with special education populations and troubled youth. As an administrator in three institutional settings for at risk youth, and within her doctoral work, the BHB theory was developed which identifies what teachers of troubled youth do to create a positive learning environment for their students. The theory offers a valuable guide in how to strengthen teacher practice for enhancing student skill sets necessary for academic success in alternative education programs.

\section{REFERENCES}

Brendtro \& duToit (2005). Response ability pathways. Cape Town, South Africa: Pretext

Burns, B. \& Hoagwood, K. (2002). Community treatment for youth. NY, NY: Oxford University Press.

Christle, C., Jolivette, K., Nelson, C. (2005). Breaking the school to prison pipeline: Identifying school Risk and protective factors for youth delinquency. Exceptionality, 13(2), 69-88.

Glasser, W. (1998). Choice Theory. NY, NY: HarperCollins Publishers.

Haggis, D. (2011). Teacher perceptions of what they do in their institutionalized settings to create a positive learning environment for troubled youth in their classrooms. Ann Arbor, MI: ProQuest.

Harvey, V. (2007). Raising resiliency schoolwide. Education Digest, 72 (7), 33-39.

Krovetz, M. (1999). Resiliency: A key element for supporting youth at risk. Clearing House, 73(2), 121-123.

Laursen, E. (2005). Rather than fixing kids - build positive peer cultures. Reclaiming Children and Youth, 14 (3), $137-142$.

Marshall, M. (2005). Discipline without stress, punishments or rewards. Los Alamitos, CA: Piper Press.

Sagor, R. (1996). Building resiliency in students. Educational Leadership, 54, (1), 38-44

Scott, T., Nelson, C., Liaupsin, C., Jolivette, K., Christle, C., Riney, M. (2002). Addressing the needs of at risk and adjudicated youth through positive behavior support: Effective prevention practices. Educatio \& Treatment of Children, 25(4), 532552.

Van Petegrm, K., Keer, H. \& Yves, R. (2008). The influence of student characteristics and interpersonal teacher behavior in the classroom on student's wellbeing. Social Indicators Research, 85, (2), 279-291.

Vincent, J.n Houlihan, D., \& Zwart, K. (1996). Using peers to increase behaviors of isolate children in school settings: An analysis of generalization effects. Behavioral Interventions, 11(2), 101-117.

Vorrath H. \& Brendtro, L. (2005). Positive Peer Culture. New Brunswick, USA \& London, UK: Aldine Transaction. 